\title{
Evaluation of bacteriology of middle ear in early quiescent stage of chronic otitis media
}

\section{R. Bhandari, ${ }^{1}$ H.Bhattarai, ${ }^{2}$ B.M Pokhrel ${ }^{3}$}

${ }^{1}$ Resident , ${ }^{2}$ Professor of Otorhinolaryngology, T.U Teaching Hospital Kathmandu, ${ }^{3}$ Professor of Microbiology, T.U Teaching Hospital Kathmandu

\section{Abstract \\ Objectives}

The objectives of this study were to determine whether any organism does exist in middle ear cavity during the early quiescent stage of chronic otitis media and to isolate their types.

\section{Materials and methods}

Forty-seven patients of age 13 years and above with diagnosis of chronic otitis media mucosal type in early quiescent stage were included. Swab was collected from middle ear cavity for culture and sensitivity in operation theatre prior to middle ear surgery and brought to microbiology laboratory within half an hour to inoculate in Blood agar, Chocolate agar and Mac Conkey agar. The isolates were identified with the use of standard bacteriological technique.

\section{Results}

Aerobic bacteria were isolated from 15 cases (31.9\%). Staphylococcus aureus isolated in 12(80\%), Pseudomonas aeruginosa in 2(13.3\%) and E. coli in 1(6.7\%).

\section{Conclusion}

Aerobic bacteria were isolated from middle ear cavity in quiescent stage of chronic otitis media in $15(32 \%)$ cases. Staphylococcus aureus was the most common organism.

\section{Key words: Bacteriology, chronic otitis media, quiescent stage, wet ear.}

\section{Introduction}

Mucosal type of Chronic Otitis Media (COM) is a common disease worldwide. There is no uniformity regarding nomenclature of this disease. Terms like Chronic suppurative otitis media-tubotympanic or noncholesteatoma type are also used synonymously. ${ }^{1}$ The disease may pass through acute, inactive, quiescent or

Correspondence: Dr Ramesh Bhandari

E-mail- therbhandari@gmail.com healed stage .There is discharge in middle ear \& external auditory canal with congestion of middle ear mucosa in acute stage. Absence of otorrhoea and normal looking middle ear mucosa are seen in inactive stage. Quiescent is that period within 6 week of cessation of frank otorrhoea where the middle ear inflammation has not yet settled completely. During its natural course, quiescent stage may convert to inactive or return to active stage as determined by various 
$R$ Bhandari et al. Evaluation of bacteriology of middle ear in early quiescent.

factors. Early quiescent stage is hereby defined within two weeks after cessation of frank otorrhoea.

Monobacterial or mixed growth is isolated from ear discharge. Pseudomonas aeruginosa, Staphylococcus aureus, Bacillus, E.coli, Haemophilus influenzae, Peptostreptococcus, Bacteroids are common bacterial organism isolated from ear discharge. Regarding the role of anaerobic organism found in COM is controversial. ${ }^{2}$ Active stage is converted to quiescent stage after medication so early quiescent stage is a relatively sterile condition. So, this study was undertaken with the aims of assessing the middle ear of its bacteriological status so that it would help to select proper antibiotics. .

\section{Materials and methods}

This is a prospective study conducted in Man Singh Memorial Academy of ENT and Head And Neck Studies and Department of Microbiology, Tribhuvan University Teaching Hospital, Institute of Medicine, Maharajgunj, Kathmandu Nepal from $1^{\text {st }}$ October 2007 to $30^{\text {th }}$ April 2009 (19 months) .Consent was taken prior to the procedure . Ethical clearance was received from Institute Review Board .Age greater than thirteen year; all gender and patient in early quiescent stage of chronic otitis media were included. Frank otorrhoea, patient receiving antibiotics within 72 hour before surgery and revision surgery cases were excluded. Non probability convenient sampling method was applied.

Preoperative work up was done with detail history, general physical examination, ear examination with otoscope and microscope if needed; tuning fork test with $500 \mathrm{~Hz}$ was done. Discharge seen in external auditory canal (EAC) was marked as frank otorrhoea. Capsule Amoxycillin (30 mg/kg/day) and ear drop Betamethasone combined with Neomycin were prescribed. Patient was asked for follow up in ENT OPD two times in a week so that exact day of stoppage of otorrhoea could not be missed. Patient was planned for surgery within 2 weeks counted from the day of stoppage of frank otorrhoea. Patient was sedated with injection Pethidine 50 miligram (mg) intramuscular and injection Promethazine25 mg intramuscular in gluteal region half an hour before surgery. Patient was kept in supine position. Ear canal was packed with sterile cotton pledget in 3 layers, and then painting was done using Povidine Iodine 5\% solution. Appropriate sized sterile metallic aural speculum was inserted in external auditory canal. Operating microscope was used to visualize the perforated tympanic membrane through which small cotton ball held by crocodile forceps were left in middle ear cavity for some time and the swab was taken. Swab was kept in sterile vial and inoculated within half an hour in culture medium in Microbiology Laboratory. Swab was inoculated in Blood Agar, Mac Conkey Agar and Chocolate Agar at $37^{\circ} \mathrm{C}$ in aerobic condition for 48 hours. Isolation and identification was done by standard technique. ${ }^{3}$ Bacterial growths was identified by morphology, culture character, pigment production, haemolysis, motility, conventional biochemical tests, Gram staining if necessary. Antibiotic sensitive test was performed by disc diffusion method for following antibiotics: Amoxycillin, Ciprofloxacin, Cloxacillin, Cotrimoxazole, Chloramphenicol, Gentamicin, Amikacin, Ceftazidime, Cefotaxim, Ceftriaxone, Erythromycin, Vancomycin. Data analysis 
was performed with help of SPSS 14.5 software package.

\section{Results}

Total number of patients enrolled for the study was 47. Age distribution is mentioned in Fig I.

Figure I: Age distribution of the patients $(n=47)$

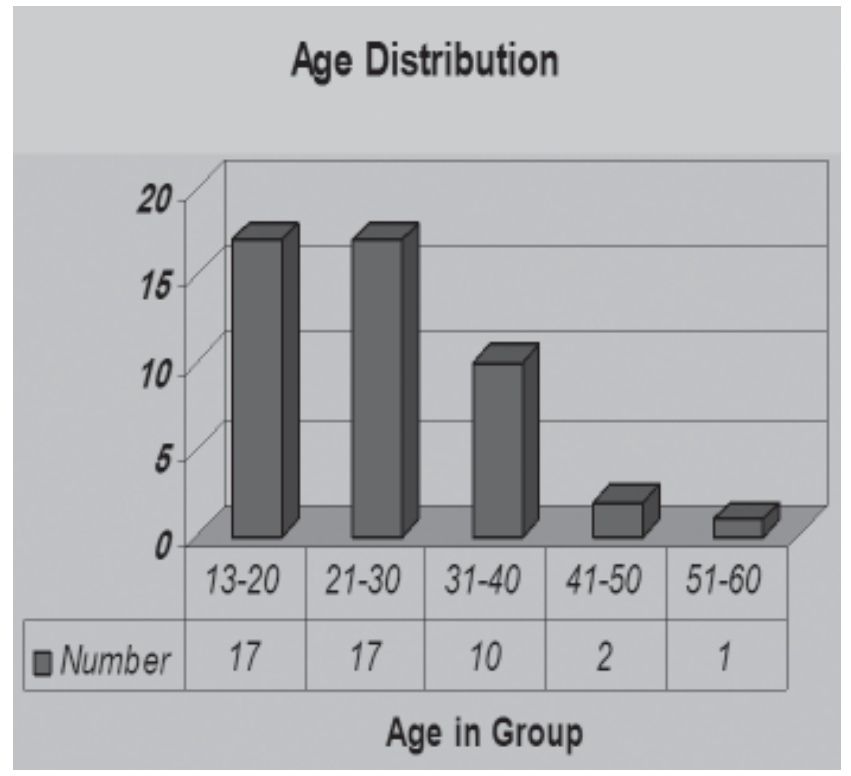

Male were 23 and female were 24 with Male: Female ratio 1:1.04

The minimum and maximum days required to stop otorrhoea after prescribing oral antibiotics and ototopical medication were 5 days and 18 days respectively with mean duration of 11.8 days. Aerobic bacteria were isolated from 15 cases (31.9\%), out of which $S$ aureus in 12 patients(80\%), $P$ aeruginosa in 2 patients(13.3\%) and Ecoli in 1 patient(6.7\%) as shown in Table1. $S$ aureus and $P$ aeruginosa were sensitive and resistant to receiving antibiotics in equal number and E.coli was resistant to the receiving antibiotics.
Table 1. Frequency and type of aerobic bacteria isolated from middle ear $(n=15)$

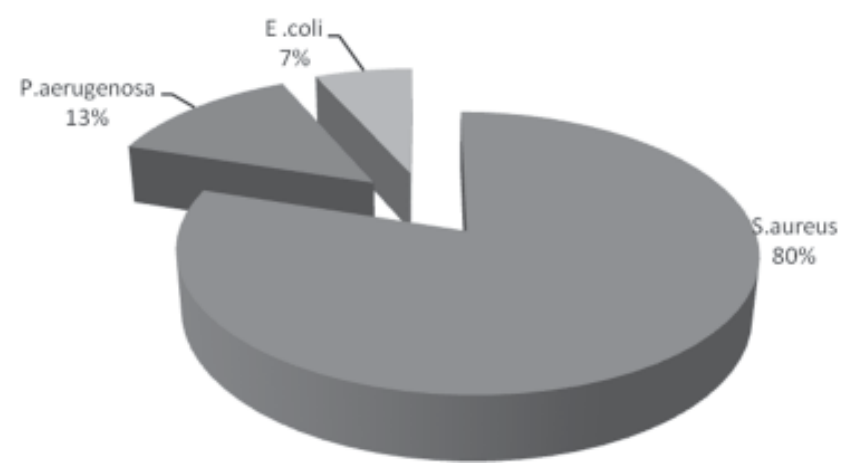

Among the patients having middle ear discharge at surgery only 14 (32.5\%) showed growth and 29(67.5\%) showed no growth at all. Similarly out of four patients having no middle ear discharge only 1 patient showed growth and culture was negative in the rest three patients as shown in Table2.

Table 2. Middle ear discharge correlated with aerobic culture

$\begin{array}{lccc}\text { Organism } & \text { No discharge } & \text { Discharge } & \text { Total } \\ \text { No growth } & 3 & 29 & 32 \\ \text { Growth } & 1 & 14 & 15 \\ \text { Total } & 4 & 43 & 47\end{array}$

Middle ear discharge was noticed in 43 ears (91.5\%). No discharge was seen in 4 cases Bacteria were isolated from 15 quiescent ears .No growth was seen in 32 ears

\section{Discussion}

The objectives of this study were to find out the aerobic bacterial status of middle ear cavity at time of middle ear surgery during early quiescent stage of COM. This 
$R$ Bhandari et al. Evaluation of bacteriology of middle ear in early quiescent.

is a prospective study. Inclusion criteria of age were kept above 12 years. Lower age group was excluded due to inconvenience to do the procedure under local anaesthasia. Patients receiving antibiotics within 72 hours before surgery were excluded from the study because it could affect culture of the organisms. Active discharging ear was converted to quiescent stage after oral and topical medication. Period of two weeks after stoppage of otorrhoea was defined as the early quiescent stage in this study. Patients were selected for procedure within either the first or second week of quiescent stage depending upon the availability in theatre. $68 \%$ samples were collected within the first week and 32\% within second week. It took five to eighteen days to control frank otorrhoea after the start of oral and oto-topical medication. Mean duration was 11.8 days. Reports are not available in literature that quote the specific period needed for the similar purpose.

All the sample collection was done in quiescent stage which is that period within 6 week of stoppage of frank otorrhoea where the middle ear inflammation has not yet settled completely. Both gram positive and gram negative bacteria are responsible to infect respiratory tract and middle ear. Aerobic bacteria were isolated from only $31.9 \%$ of quiescent ears. Staphylococcus aureus was the most common organism (80\%) isolated, followed by Pseudomonas aeruginosa (13.3\%) and E. coli (6.7\%). All the growths were as monobacterial. Pseudomonas aeruginosa was the most common organism isolated from chronic discharging ears in some of the studies ${ }^{4,5,6}$ while Staphylococcus aureus was the commonest organism isolated in studies done by others. ${ }^{7,9}$ Polymicrobial infections including fungi are also isolated from chronic otitis media as a symbiotic relation with aerobic organisms. Swab was innoculated within half an hour to preserve the fastidious organism like H.influenzae. Regarding sensitivity, Saureus and Paeruginosa were sensitive and resistant to receiving antibiotics in equal number and E.coli was resistant to the receiving antibiotics.

Aerobic bacteria like staphylococcus, proteus, pseudomonas, E. coli were reported from various studies with varying frequency from frank discharge before using any form of antibiotics. ${ }^{6,7,8}$ Varshney et $\mathrm{al}^{8}$ isolated Pseudomonas aeruginosa ( 35.71\%), Staphylococcus aureus (19.52\%), E. coli (5.74\%) but Rao et $\mathrm{al}^{9}$ isolated Staphylococcus aureus( 42.5\%), Pseudomonas aeruginosa(18.33), and E. coli( $10 \%)$. Prior use of antibiotics yields lower isolates. More resistant nature of Staphylococcus aureus to empirical therapy could be the one reason for most frequent isolate in our study. Pseudomonas does not normally inhabit the upper respiratory tract so its existence in middle ear cavity indicates possible invasion through perforated tympanic membrane in COM. It attaches with pilli, releases protease, lipopolysaccharide and other inflammatory enzymes preventing normal immunological defense and eroding bones in middle ear.

Presence of organism in middle ear during surgery may affect the outcome of surgery. Discharge seen in middle ear during surgery in quiescent stage is not always the source of infection. In our study, aerobic bacteria were isolated only from 15(31.9\%) ears. This low yield may be due to oral antibiotics and ototopical medication used to make the ear quiescent. Our findings are different from those of Carlin et al ${ }^{10}$ who had observed 
that out of 60 wet ears only in 11(18.3\%) pathogens were actually present but condition of middle ear is different in our study. Retrospective study conducted in korea by Ahn et $\mathrm{al}^{11}$ for evaluation of pre, intra and post operative status of bacteria from middle ear revealed that no bacteria were observed in $34.1 \%$ of preoperative or $76.6 \%$ of intraoperative cultures. Patients preoperatively positive for coagulase-negative Staphylococcus, S. aureus, or Pseudomonas aeruginosa remained positive intraoperatively .different types of bacteria isolated from middle ear intra operatively, not seen preoperatively, methicillinresistant Staphylococcus aureus (MRSA) being the most common preoperatively. Study from Nigeria in $\mathrm{CSOM}^{12}$ showed Escherichia coli and Streptococcus $s p$. are the leading pathogenic organisms in their region.

\section{Conclusion}

It can be concluded that organisms were isolated in $31.9 \%$ of middle ear cavity at surgery in early quiescent stage of COM. Most common aerobic bacteria found in middle ear cavity in early quiescent stage was Staphylococcus aureus (80\%), followed by $P$. aeruginosa and E.coli which were seen in 13.3\% and $6.7 \%$ of cases respectively.

\section{References}

1. Browning GG, Merchant SN, Kelly G, et al. Chronic otitis media. Scotts-Brown's Otorhinolaryngology, Head and Neck Surgery, $7^{\text {th }}$ edition.London: Edward Arnold publisher Ltd; 2008:3345-95.

2. Browning GG, Picozzy GL, Sweeney G and Galder I.T: Role of anaerobe in chronic otitis media. Clin Otolaryngol 1983; 8:47-51.

3. Collee JG, Miles RS, Watt B. Test for identification of bacteria. In: Collee JG, Fraser AG, Marmion
BP, Simmons A. Mackie and McCartney practical medical microbiology. $14^{\text {th }}$ ed. London: Livinstone, 1996: 131-49.

4. Sinha et al. Aerobic bacteriological study of chronic otitis media. Indian Journal of Otology 1999; 5: 203-6.

5. Sharma S, Regan HS, Goyal A, et al. Bacteriological profile in chronic suppurative otitis media in Eastern Nepal. Trop Doct 2004; 34(2):102-4.

6. Vijaya D, Nagarathnam T. Microbiological study of chronic suppurative otitis media. Indian Journal of Otology 1998; 4: 172-14.

7. Fatma A, Assiry S, Zakzour .S. Microbiological evaluation and aspect on management of chronic suppurative otitis media in Riyadh. Indian Journal of Otology 1998; 4:115-120.

8. Varshney S, Gupta P. Bacteriological study of chronic suppurative otitis media. Indian Journal of otology 1999; 5: 87-91.

9. Rao B.N, Reddy M.S. Chronic suppurative otitis media- prospective study. Ind J Otol. and Head andNeck Surg1994; 3: 8-11.

10. Carlin WV, Lesser TH, John DG. Systemic antibiotic prophylaxis and reconstructive ear surgery. Clin Otolaryngol 1987; 12: 441-6.

11. Ahn JH, Kim MN, Suk YA, et al. Preoperative, intraoperative, and postoperative results of bacterial culture from patients with chronic suppurative otitis media. Otol Neurotol. 2012; 33(1):54-9.

12. Adoga AA, Bakari A, Afolabi OA, Kodiya AM, Ahmad BM. Bacterial isolates in chronic suppurative otitis media: a changing pattern? Niger J Med. 2011; 20(1):96-8. 